\title{
LA INCIDENCIA DEL FINANCIAMIENTO A LAS OSC AMBIENTALISTAS DE ENSENADA EN SUS ESQUEMAS DE CONTRATACIÓN
}

INCIDENCE OF FINANCING TO ENVIRONMENTAL CSOs OF ENSENADA IN THE CONTRACTING OF ITS COLLABORATORS

Karen Elizabeth Sandoval Liera ${ }^{1}$

ksandoval@uabc.edu.mx

Alma Alejandra Soberano Serrano ${ }^{2}$

alma.soberano@uabc.edu.mx

Universidad Autónoma de Baja California, Facultad de Ciencias

Administrativas y Sociales, México 
Para citar este artículo:

Sandoval L. Karen, Soberano A. (2020). La incidencia del financiamiento a las OSC ambientalistas de Ensenada en sus esquemas de contratación. Espacio I+D, Innovación más Desarrollo. IX(23), 20-38. doi: http://dx.doi.org/10.31644/IMASD.23.2020.a02

\section{RESUMEN}

El propósito de esta investigación es determinar si existe una relación entre las fuentes de financiamiento que reciben las Organizaciones de la Sociedad Civil (osc) con actividades ambientalistas en Ensenada, Baja California y el régimen de contratación del personal. Los resultados obtenidos indican que las fuentes de financiamiento que reciben las osc no son un factor que influya en la elección del régimen fiscal de los trabajadores; asimismo, se encontró que los directivos de las osc conocen adecuadamente los regímenes fiscales existentes en México y, por último, se ubicó que el régimen fiscal más utilizado es el de sueldos y salarios. Con lo anterior se concluye que los directivos tienen el conocimiento necesario para la elección del régimen de contratación.

\section{Palabras Clave}

Financiamiento, Organizaciones de Sociedad Civil, contratación. 


\section{- Abstract-}

The aim of this investigation was to determine if there is a relationship between the sources of funding received by Civil Society Organizations (csos) and environmental activities in Ensenada, Baja California and the personnel hiring regime. This after the application of a questionnaire with quantitative and descriptive analysis. The results indicate that the sources of financing received by csos are not a factor that influences the choice of workers' tax regime; Likewise, it was found that cso managers know adequately the existing tax regimes in Mexico and, finally, it was found that the most used tax regime is that of wages and salaries. With the above, it is concluded that managers of csos have the necessary knowledge to choose the hiring regime.

\section{Keywords}

Financing, Civil Society Organizations, hiring. 
$\mathrm{E}$ n la actualidad es común que los ciudadanos se organicen para cubrir necesidades sociales que el gobierno omite, dando origen a las Organizaciones de la Sociedad Civil (osc), quienes disponen de recursos humanos y financieros otorgados por donaciones o diversas fuentes de financiamiento procedentes de instituciones internacionales, nacionales o de ciudadanos para su funcionamiento.

Las osc son agrupaciones sin fines de lucro, legalmente constituidas, que operan con colaboradores sujetos a diversos tipos de relaciones laborales, incluyendo la figura de los voluntarios. Las relaciones laborales existentes en las osc representan una oportunidad de investigación debido a:

1) la falta de una ley especializada que regule las relaciones laborales en las osc en México;

2) el desconocimiento y poco entendimiento de cada uno de los regímenes fiscales que hay de contratación, de acuerdo a la ley, por parte de los dirigentes de las osc, lo que puede generar que no se contrate de forma adecuada al personal;

3) la inexistencia de contratos firmados que protejan la relación laboral y;

4) la limitación presupuestal para la contratación de personal que implican las fuentes de financiamiento con las que cuenta la osc.

Por ello, se presenta la siguiente pregunta de investigación: ¿Existe alguna relación entre los financiamientos existentes para la operación de las osc y la forma en que contratan a sus colaboradores?

La hipótesis inicial es que el desconocimiento por parte de los directivos de las organizaciones de la sociedad civil con actividades ambientalistas sobre los diversos regímenes fiscales de remuneración, hace que no se tenga la correcta gestión del recurso humano y que, por ende, exista poca formalidad laboral al momento de la contratación del personal.

El presente estudio se sustenta en el hecho de que las osc pueden convertirse en una fuente generadora de empleos, siempre y cuando se satisfagan las necesidades sociales para las que fueron creadas, lo que en ocasiones genera una manera de autoempleo y profesionalización que va dirigida a cubrir las demandas específicas de la sociedad a las que se pretende dar respuesta; sin embargo, estos empleos son por tiempo determinado o indeterminado, en ocasiones mal remunerados y sin prestaciones de ley.

Este trabajo caracteriza y define los regímenes fiscales y fuentes de financiamiento más comunes en las osc, con el objetivo de que, con los resultados obtenidos, se ayude a los directivos y administradores a que conozcan a detalle cada uno de éstos, y que entiendan de manera clara y sencilla cuando debe considerarse a una persona como trabajador según la ley y cuándo no, a pesar de que en la práctica se le trate como tal. 


\section{CONCEPTOS RELEVANTES}

\subsection{Las Organizaciones de la Sociedad Civil}

Las osc se definen como organizaciones ciudadanas libres y voluntarias que a partir de la identificación de campos específicos de la vida social realizan acciones tendientes al bienestar colectivo, influyendo en las decisiones públicas y en su normatividad. Son agrupaciones estables, organizadas y con estructura, reglas de funcionamiento y objetivos que tienden a profesionalizar las acciones que realizan, y que en la mayoría de los casos cuentan con personalidad jurídica (Nava, 2016).

El gobierno ha implementado medidas regulatorias tanto para su organización como su administración, otorgándoles incluso un trato fiscal especial; estas organizaciones representan un puente de unión entre el desarrollo social y el profesional, así como una alternativa de empleo para todos (De Nieto, 2009). En estas Organizaciones convergen diversos tipos de relaciones laborales, tales como los asalariados (los que reciben un pago sin importar el régimen) y el voluntariado (quien no recibe pago económico por su labor) otorgando así a los asalariados competencias técnicas y a los voluntarios actividades más humanistas.

Las remuneraciones otorgadas a los empleados asalariados pueden ser: a) Asalariados con seguridad social por tiempo indefinido; b) Asalariados sin prestaciones de seguridad social por proyectos, asalariados a medio tiempo; c) Régimen de honorarios y las consultorías y d) Voluntariado, que refiere a las personas que apoyan en las actividades de los proyectos sin recibir una paga.

La naturaleza de las fuentes de financiamiento con las que operan las osc puede afectar el pago de las contraprestaciones a sus trabajadores, ya que el recurso con el que operan no cubre el pago de la seguridad social, sino que únicamente contemplan el pago del neto por recibir; lo anterior resulta un problema en dos sentidos: por un lado, en la omisión al pago de la seguridad social para los trabajadores, y, también, en la necesidad para las osc de gestionar correctamente el personal con los recursos que disponen, resultando por lo general en la contratación de algún seguro privado de salud por parte de los trabajadores.

\subsection{Las Relaciones Laborales y sus regímenes fiscales}

Köhler y Artiles (2007) definen las relaciones laborales como aquéllas compuestas por la institución, las reglas y normas que regulan la vida social en institución y la economía general, en la cual interactúan actores 
individuales (empresarios- empleado) y colectivos (asociaciones patronales, sindicales con la intervención de estado).

El artículo 20 de la Ley Federal del Trabajo (LFT), indica que estas relaciones están sujetas a un contrato; sin embargo, también entiende que existe una relación de trabajo cuando haya una persona obligada a prestar un servicio de forma personal y subordinada, y otra que tenga que pagar un salario por la contra prestación recibida. Esta ley permite como formas de contratación el trabajo por tiempo determinado, por obra determinada, por tiempo indeterminado, por capacitación inicial y a prueba; si no se estipula se entiende la contratación como de tiempo indeterminado.

Las relaciones laborales están integradas por el trabajador, persona física que presta sus servicios de manera personal y subordinada a cambio de una remuneración y por el patrón, persona física o moral que recibe los servicios y se obliga a pagar un sueldo o salario, además de tener la facultad jurídica de autoridad y mando.

Pérez y Fol (2017), dicen que se considera subordinación cuando se observan los siguientes elementos: 1) se otorgan al trabajador equipo o útiles; 2) está sujeto a una jornada laboral, días de descanso y vacaciones, así como las demás prestaciones que se derivan de un contrato laboral; 3) haya supervisión del patrón 0,4 ) exista un reglamento interior de trabajo.

\subsubsection{Asalariados}

El Servicio de Administración Tributaria (sAT, 2014), organismo rector en los esquemas impositivos a las contrataciones en nuestro país, define a los asalariados como a las "personas físicas que perciben salarios y demás prestaciones derivadas de un trabajo personal subordinado a disposición de un empleador, incluyendo la participación de utilidades y las indemnizaciones por separación de su empleo".

Este régimen otorga derechos y prestaciones de seguridad social a quienes tributen como asalariados, con la finalidad de "mejorar la calidad de vida en el aspecto económico social de los trabajadores” (Garduño, Hernández y Ramírez, 2012). Para el SAT, cualquier persona física que presta un servicio subordinado y a disposición de un empleador y con un horario establecido es asalariado.

\subsubsection{Persona física con Actividad Profesional}

En México este tipo de prestación de servicios es regulado por el Derecho Civil, y se celebra mediante un contrato privado, en el cual el profesionista presta sus servicios profesionales a otro a cambio de un pago denominado para este régimen como honorario (De Buen, 2005). En este régimen no hay 
subordinación, ya que está pensando para personas que prestan sus servicios profesionales con autonomía de conocimientos y de recursos.

El artículo 100 de la Ley del Impuesto Sobre la Renta (LISR) considera ingresos por prestación de servicios profesionales: "las remuneraciones que se deriven de prestar un servicio personal independiente".

Claudia de Buen (2005) señala que este contrato es usado por los patrones mexicanos para la evasión de las cargas laborales originadas por los "trabajadores de planta", tales como las cuotas al Instituto Mexicano del Seguro Social (IMSs), al Instituto del Fondo Nacional de la Vivienda para los Trabajadores (INFONAVIT) y demás prestaciones laborales; así mismo, mediante este esquema, el patrón se libera de la obligación del pago de finiquito en caso de despido o por la terminación de las relaciones laborales, ya que no crea una antigüedad. También conocido como régimen de honorarios, se diseñó como opción de contratación para necesidades esporádicas, temporales, por proyectos o por un servicio de consultoría que requieren a profesionales para su desempeño; sin embargo, en la actualidad, este tipo de contratación se ha desvirtuado, ya que se contrata por este régimen a personal que desempeña puestos permanentes.

\subsubsection{Honorarios asimilables al salario}

Mediante este régimen se pagan los servicios profesionales de aquellas personas que manifiestan por escrito su decisión de tributar en el régimen de honorarios asimilables al salario, lo cual beneficia al prestador de servicios porque no le genera cargas fiscales más allá del impuesto sobre la renta (ISR). En los últimos años esta figura se ha empezado a usar más para efectuar el pago de personal de confianza, de cargos altos, administrativos, vendedores entre otros, con el fin de evitar pagar los altos costos del pago de las prestaciones de seguridad social.

La LISR no hace distinción alguna entre el régimen honorarios profesionales y los honorarios asimilables al salario.

\section{FUENTES DE FINANCIAMIENTO}

Las fuentes de financiamiento son aquellas formas con las cuáles la osc obtiene los recursos que le permiten cumplir con sus objetivos (Mejía, 2016). Los recursos son todos los medios que la osc utiliza para alcanzar sus fines sociales, los recursos pueden ser tangibles e intangibles. Dentro de los recursos tangibles están los recursos financieros, que son aquellos recursos que tienen la capacidad de convertirse en efectivo (Gavilán, Iglesias y Beitia, 2013).

Las osc obtienen sus recursos a través de 1) gestiones para los recursos propios; 2) financiamientos por convenios públicos o privados; 3) convenios con ong u organismos internacionales. 
Se habla de recursos propios de las osc cuando provienen de cuotas de sus socios, de donaciones, de legados de particulares, la venta de productos, de campañas de recaudación de fondos, etc.

Las osc pueden financiarse también a través de Convenios con administraciones públicas, mediante licitaciones o proyectos de colaboración (Gavilán, et al., 2013); en estos, ambas partes negocian y establecen requisitos y alcances necesarios para satisfacer necesidades, sobre todo sociales.

Existen apoyos y convenios con particulares cuando los financiamientos son otorgados a las osc por las empresas que patrocinan la causa social que defienden (Gavilán, et al., 2013). Estos apoyos por lo general son a fondo perdido, y son esporádicas.

Otra forma de financiamiento ocurre a través de Convenios con otras ONG o fundaciones, financiamientos otorgados a través de contratos mediante los cuales una fundación, nacional o internacional, da financiamiento o cede una parte de sus recursos para que se desarrollen proyectos sociales. Con esta fuente se desarrollan convenios de colaboración (Gavilán, et al., 2013).

\section{MARCO LEGAL}

En México existe la libertad de asociación, es decir, las personas pueden asociarse en figuras jurídicas plenamente constituidas dando origen a las Personas Morales, las que pueden ser mercantiles o no. Una organización sin fines de lucro puede ser tanto una Asociación Civil (AC), como una Organización de la Sociedad Civil o una Organización No Gubernamental (ONG).

El Código Civil Federal (CCF) es el ordenamiento que prevé la existencia de Asociaciones Civiles; en su artículo 2670 las define como la asociación de dos o más individuos, con una duración no transitoria, un fin común y sin carácter económico; deben constituirse por escrito, a través de un Acta Constitutiva que debe inscribirse en el Registro Público de la Propiedad, otorgándosele así personalidad jurídica. También dentro del CCF se encuentra regulada la prestación de servicios profesionales, forma de contratación más utilizada para las personas que trabajan en una AC en nuestro país, bajo el esquema de Régimen de Honorarios explicado en el numeral 2.2.2 de este documento.

Como se ha mencionado, la LFT tiene como objeto regular las relaciones de trabajo derivadas del artículo 123 de la Constitución Política de los Estados Unidos Mexicanos (CPEUM), indicando todas las condiciones, requisitos y prestaciones existentes en las relaciones laborales, así como la necesidad de formalizar las contrataciones por escrito y sus formas de terminación.

Establece los Derechos y obligaciones tanto de los empleados como de los patrones y, cobra particular importancia para este trabajo, la regulación que hace de los sueldos y salarios. 
Por su parte, la Ley del Seguro Social (LSs) establece que la seguridad social está constituida por una serie de Derechos de los trabajadores que deben ser otorgados por los patrones, tales como el derecho a la salud, a la asistencia médica, a la protección de los medios de subsistencia, a los servicios sociales necesarios y a una pensión para el retiro, derechos que deben ser garantizados por el Estado. La Lss regula las prestaciones de seguridad social a las que tienen derecho todos los trabajadores que tributan en el régimen de sueldos y salarios.

La LISR tiene por objeto definir qué personas están obligadas al pago de impuestos por la actividad económica que desarrollan; establece que las personas físicas con actividades empresariales y profesionales que se encuentran dentro del régimen de honorarios están obligadas a tributar.

\section{METODOLOGÍA}

Este estudio utilizó un enfoque cuantitativo descriptivo; la recolección de datos se realizó mediante la aplicación de un cuestionario a los directivos y administrativos de las osc, el diseño de investigación que se utilizó fue transaccional descriptivo.

La población seleccionada fue la constituida por las osc con actividades ambientalistas de Ensenada, B.C; las personas que integraron la muestra son los directores ejecutivos y personal administrativo que laboran en estas osc, buscándose que los participantes fueran tomadores de decisiones en las organizaciones. Para obtener un panorama lo más cercano posible a la realidad, se buscó la participación de cuando menos un integrante de cada osc registradas en el Sistema de Registro Federal de Organizaciones de la Sociedad Civil (SIRFOSC).

Los ítems que conformaron este cuestionario fueron de opción múltiple, dicotómicos y de respuesta abierta. El instrumento consistió en un cuestionario semiestructurado, aplicado al personal administrativo y de dirección, el cual nos permitió analizar el conocimiento de nuestras variables y al mismo tiempo indicó algunos factores que influyen en la selección del régimen de contratación.

El instrumento elaborado para este estudio de caso fue sometido a un proceso de validación por jueceo, el cual determinó que el instrumento cumplía con los criterios de claridad, coherencia, relevancia y suficiencia; para la selección de los jueces se tomó en cuenta la experiencia laboral y académica, tanto en relación con el sujeto de estudio como en la elaboración de investigaciones de carácter científico, el grado académico y la disponibilidad para apoyar. 


\subsection{Procedimiento de recolección de datos}

El instrumento final se envió por correo electrónico a las 21 osc con actividades ambientalistas registradas, los correos fueron obtenidos de la base de datos del SIRFOSC, acompañado por una carta de presentación, donde se explicaba el objetivo general y los específicos de este estudio de caso, y los datos de contacto de la responsable de la investigación; asimismo se les puso una fecha límite de respuesta.

El instrumento fue auto administrado por cada participante desde su equipo de cómputo, mediante la aplicación denominada "Google Formularios", para facilitar la elaboración de la base de datos.

Para la recolección de datos, fue necesario en algunos casos mandar recordatorios de la solicitud de apoyo enviada, también se les contactó por medio de alguna red social y otros casos se les hicieron llamadas telefónicas. Una vez llegada la fecha límite de respuesta se cerró el cuestionario y se procedió la elaboración de la base de datos en Excel.

\section{RESULTADOS}

Con relación a si los directivos y administrativos de las osc entienden de manera correcta la contratación utilizada en estas organizaciones, $100 \%$ de las personas encuestadas saben que la ley que regula las relaciones laborales es la Ley Federal del Trabajo.

Como regla general, hay un buen conocimiento de cada uno de los regímenes fiscales vinculados a la contratación por parte de los directivos y administradores de las osc, pues en el caso del régimen de sueldos y salarios $89 \%$ de los encuestados conocen y entienden este régimen y solo $11 \%$ no.

En el régimen de contratación de Honorarios Profesionales 94\% de los encuestados lo entienden y lo conocen mientras que solo $6 \%$ de las personas encuestadas no lo conoce y no lo entiende. Por último, se observa que en el régimen de contratación por honorarios asimilables al salario $83 \%$ lo conocen y lo entienden y solo $17 \%$ no lo conocen y no lo entienden.

En la gráfica 1 podemos observar que cuando se les preguntó si existe una relación laboral conforme a los regímenes utilizados, en la respuesta otorgada para el régimen de contratación por sueldos y salarios $72 \%$ de los encuestados dicen que sí existe una relación laboral, 17\% dicen que no existe y solo $11 \%$ no saben si existe o no.

Mientras que para el régimen de contratación por honorarios profesionales solo $17 \%$ dijeron que sí existe una relación laboral, $72 \%$ de los encuestados dicen que no existe y $11 \%$ no saben si existe o no. Por último, para el régimen de contratación por honorarios asimilables al salario, $44 \%$ dice que sí existe una relación laboral y 56\% de los encuestados dicen que no existe. 


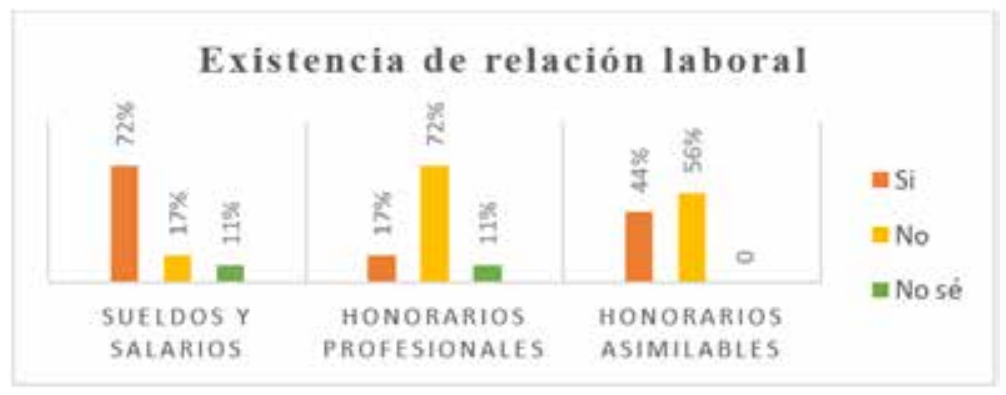

Gráfica 1. Existencia de relación laboral por régimen de contratación. Fuente: Elaboración propia con datos obtenidos de la encuesta

$78 \%$ de los encuestados manifestó saber cuál es la ley que regula las relaciones laborales del régimen de sueldos y salarios, mientras que $22 \%$ dijo desconocerlo. Sin embargo, 33\% de los encuestados piensan que el régimen de honorarios profesionales es regulado por la LFT, 39\% saben que la ley que regula los contratos por honorarios profesionales es la LISR, 6\% de los encuestados piensa que éstos son regulados por el CCF y $22 \%$ no saben cuál es la ley que regula los servicios profesionales.

En la gráfica 2 se observa cómo $44 \%$ de las personas encuestadas dicen que de acuerdo a sus conocimientos, el criterio utilizado para contratar por el régimen de honorarios profesionales es cuando no requieren supervisión, porque no hay subordinación y porque es para un proyecto específico. 33\% dice que porque es un trabajo muy especializado y por el monto aprobado por la fuente de financiamiento. $6 \%$ dice que debido a la elegibilidad que tenga la persona, otro $6 \%$ dice que en la osc siempre se contrata bajo este régimen. Por último, el 11\% dice que no contratan por este régimen.

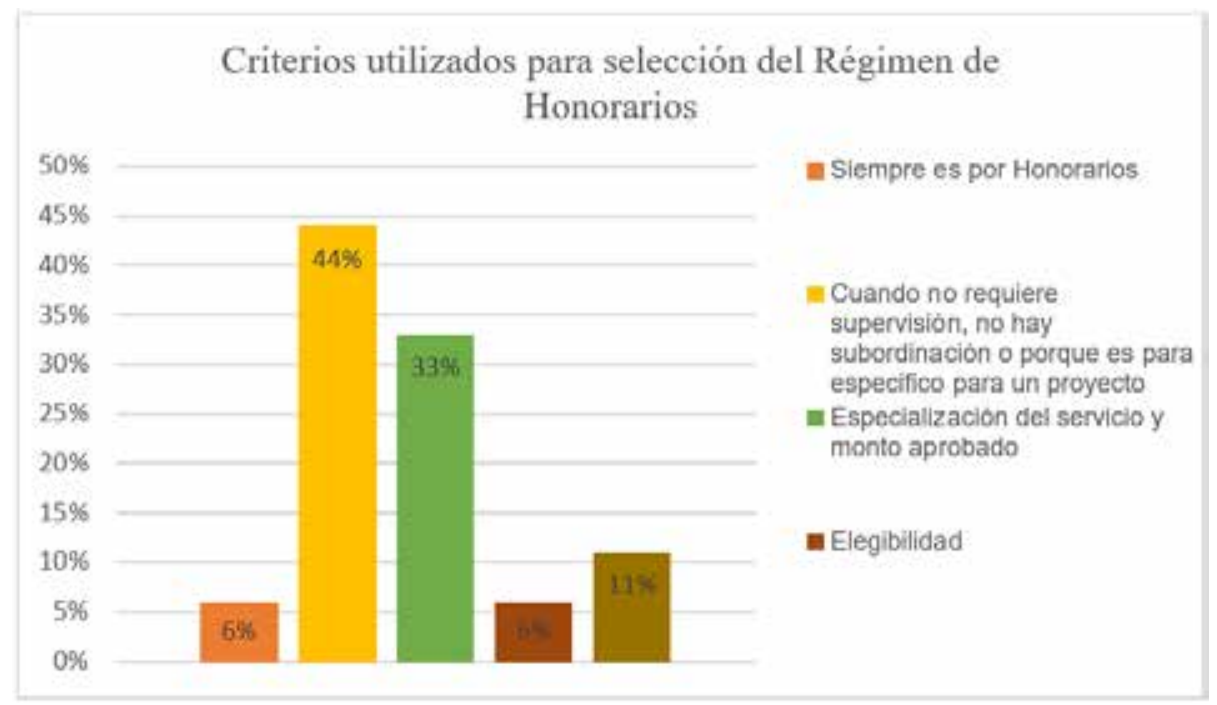

Gráfico 2. Criterios para selección del régimen de honorarios profesionales. Fuente: Elaboración propia con datos obtenidos de la encuesta 
En el gráfico 3 podemos ver que 33\% de los encuestados contestaron que en la osc que laboran y de acuerdo a los conocimientos que tienen el criterio utilizado para la contratación por el régimen de honorarios asimilables al salario depende de la necesidad técnica y del proyecto, $5 \%$ contestó que porque el puesto para el que se contrata no está en el organigrama. 17\% respondió que porque es por un tiempo o producto determinado. Otro 5\% dice que es porque así lo recomienda el contador o el abogado. 17\% dice que lo hacen porque el servicio que se quiere contratar no es un servicio profesional. El 6\% dice que de acuerdo a la elegibilidad y por último otro $17 \%$ dice que no contratan bajo este régimen.

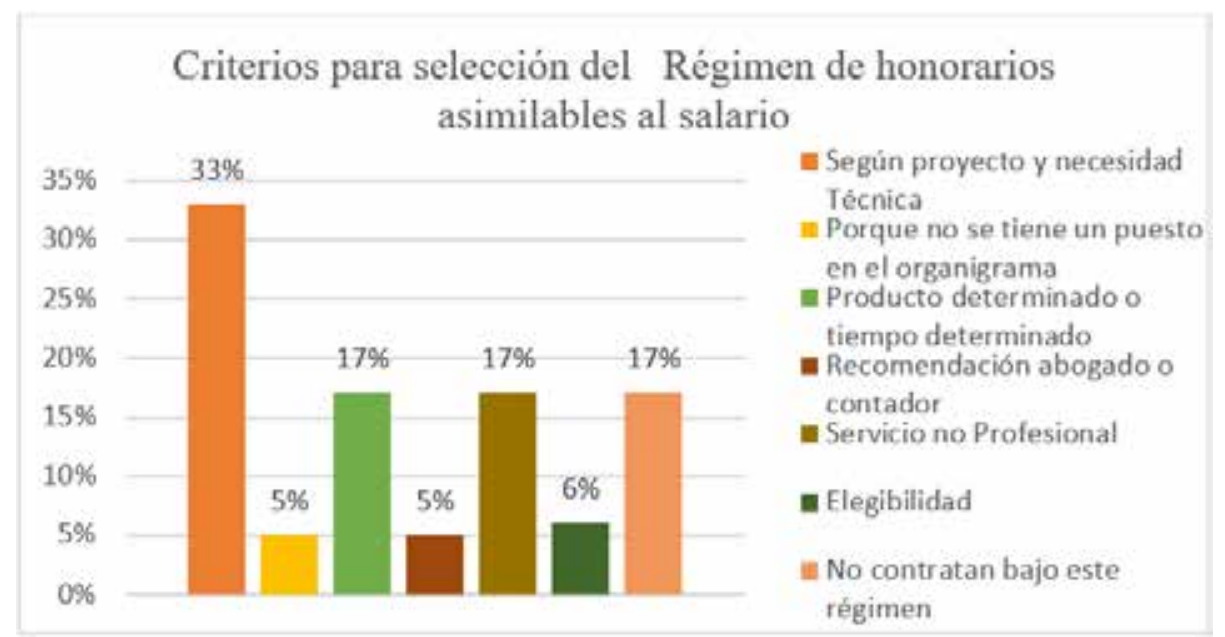

Gráfico 3. Criterios para selección del régimen de honorarios asimilables al salario. Fuente: Elaboración propia con datos obtenidos de la encuesta

En el apartado diseñado para establecer si existe una relación entre las fuentes de financiamiento y los regímenes fiscales en la elección del régimen fiscal de los colaboradores en las osc con actividades ambientalistas en Ensenada, B.C, las respuestas fueron las siguientes:

El 17\% de los encuestados contestaron que en la osc en la que laboran reciben solo una de las 4 fuentes de financiamiento que se les presentó, 39\% dice que recibe 2 de las $4,27 \%$ reciben 3 de las 4 y otro $17 \%$ dice recibir las 4 fuentes de financiamiento.

El 44\% de los encuestados contestaron que en la osc en la que laboran se usan 3 regímenes fiscales, el 22\% dice que manejan 2, 6\% que manejan solo uno y $28 \%$ no contratan.

En el gráfico 4 se puede apreciar que $33 \%$ de las personas encuestadas contestaron que en la osc que laboran del total de los recursos propios se destinan entre $1 \%$ y $20 \%$ al pago de colaboradores, $33 \%$ contestaron que de los ingresos por convenios con administración pública destinan entre $1 \% \mathrm{y}$ $20 \%$ para este rubro, y $28 \%$ personas contestaron que de los recursos por 
convenios con osc o fundaciones destinan entre $1 \%$ y $20 \%$ para el pago de colaboradores.

Para el caso de los convenios con administración pública podemos observar que $39 \%$ de las personas encuestadas contestaron que en la osc que laboran destinan en promedio entre $21 \%$ y $40 \%$ de los ingresos recibidos para el pago de colaboradores, y que $28 \%$ de los encuestados dicen que de los recursos obtenidos por convenios con otras osc o fundaciones destinan al pago de los colaboradores entre $21 \%$ y $40 \%$.

De los encuestados solo 5\% señaló que de los recursos propios generados destinan $41 \%$ y el $60 \%$ para el pago de los colaboradores; para los convenios con administración pública $6 \%$ dijo que se destina entre $41 \%$ y $60 \%$, y solo $11 \%$ de las personas encuestadas contestaron que de los recursos obtenidos por convenios con otras osc o fundaciones destinan entre $41 \%$ y $60 \%$ al pago de colaboradores.

El 5\% de las personas contestaron que en la osc que laboran, de los recursos provenientes de convenios con otras osc o fundaciones se destina entre $61 \%$ y $80 \%$ para el pago de colaboradores.

También se les dio la opción de no contestar ya sea porque no reciben alguna de estas fuentes de financiamiento o porque prefirieron no contestar por considerar la información delicada. De la fuente de financiamiento que se obtuvieron más abstenciones fue de los recursos propios con 33\%, mientras que los recursos generados con administración pública y convenios con otras osc o fundaciones hubo una abstención de $17 \%$ respectivamente, los que decidieron no contestar.

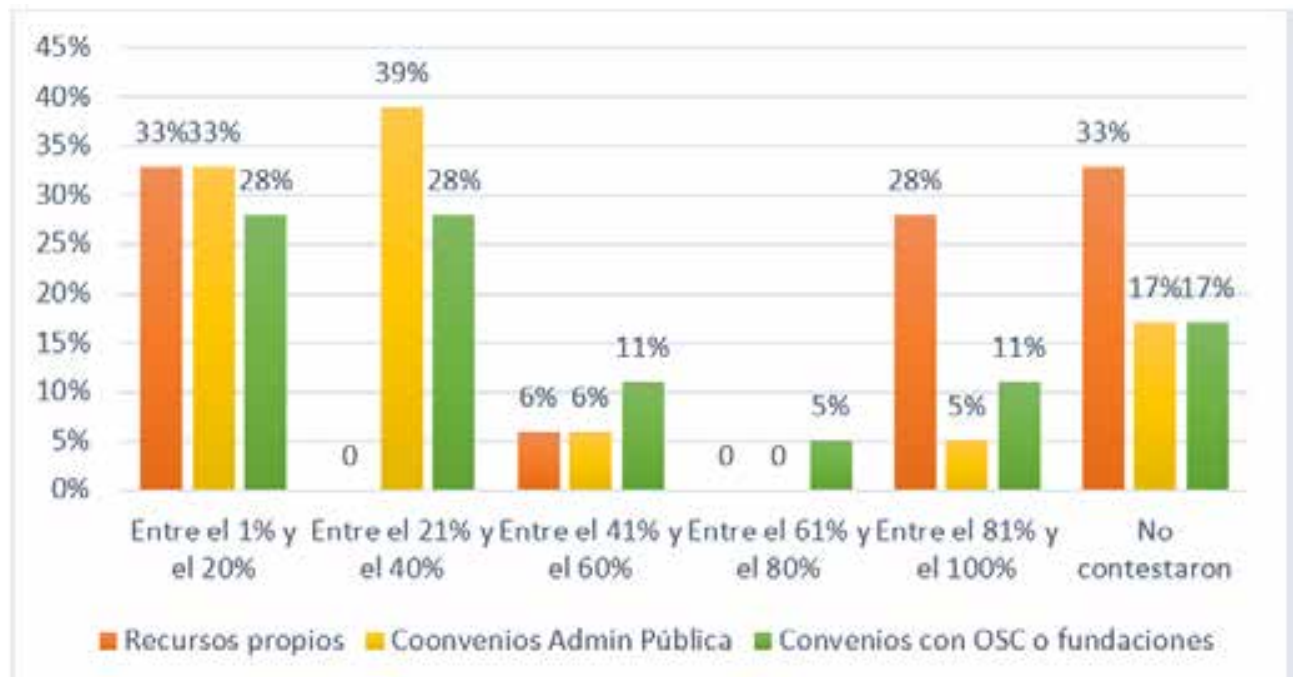

Gráfico 4. Porcentaje que destinan las OSC en los pagos de los colaboradores por fuentes de financiamiento. Fuente: Elaboración propia con datos obtenidos de la encuesta 
En el gráfico 5 podemos observar que $44 \%$ de las osc definen el régimen de contratación de acuerdo al presupuesto aprobado, 39\% de acuerdo a las fuentes de financiamiento, $6 \%$ de las personas dijo que la definición del régimen de contratación dependía del monto a pagar de impuestos.

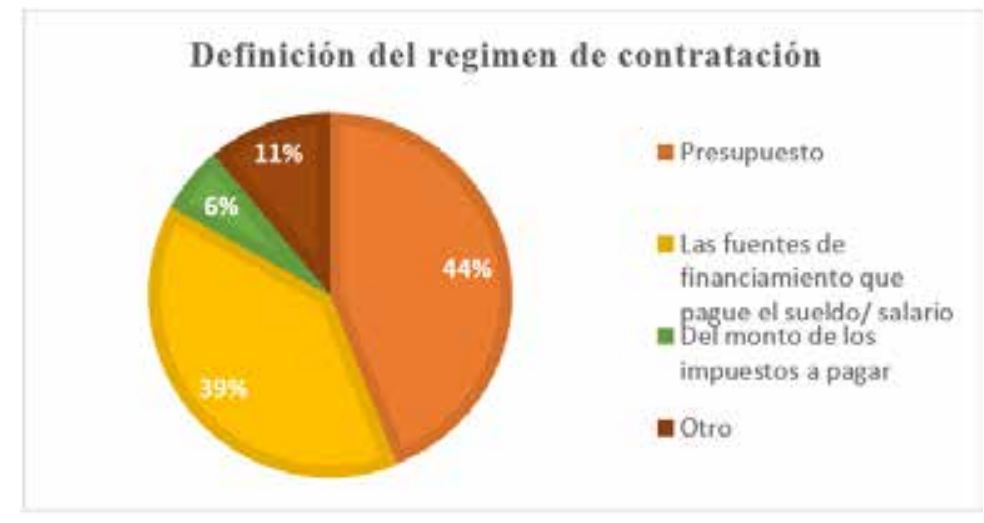

Figura 5. Definición del régimen de contratación en las OSC. Fuente: Elaboración propia con datos obtenidos de la encuesta

Para conocer cuál es el régimen fiscal más utilizado en las osc con actividades ambientalistas en Ensenada, B.C, los resultados fueron los siguientes: El $50 \%$ de los encuestados contestaron que en su osc el régimen de contratación más utilizado es el de sueldos y salario, después le sigue el régimen de honorarios profesionales con $22 \%, 17 \%$ de los encuestados constaron que el régimen que más utilizan son honorarios asimilables al salario y solo $11 \%$ prefirieron no contestar.

Al preguntarles por qué optan por ese régimen, el 39\% de los encuestados contestaron que el régimen que más utilizan es el de sueldos y salarios, porque quieren dar mayor seguridad laboral al trabajador y a la osc, también para cumplir con la ley y porque existe una subordinación entre la osc y el trabajador. El 17\% contestó que el régimen de honorarios profesionales y honorarios asimilables porque no tienen un ingreso seguro y todo depende de los proyectos que se les apruebe. Otro 17\% indicó que no se contrata bajo ningún régimen, el 5\% contestó que el régimen más utilizado es el de honorarios asimilables al salario, porque se contratan más eventuales y por último un $22 \%$ se reservó su respuesta.

El 33\% de los encuestados manifestó tener un entre 1 y 5 colaboradores, sin importar el régimen de contratación, $22 \%$ dice tener entre el 6 y 10 colaboradores, $11 \%$ entre 11 y 15 colaboradores, $6 \%$ entre 16 y 20 colaboradores y $28 \%$ más de 21 colaboradores; sin embargo, 63\% de los encuestados contestaron que en la osc en la que laboran existen contratos firmados, $28 \%$ dice no tener y $11 \%$ dice que firma con algunos. 


\section{CONCLUSIONES Y RECOMENDACIONES}

Se encontró que los directivos y administrativos encargados de tomar las decisiones de la selección del régimen de contratación manejan un conocimiento básico adecuado en dos de los tres regímenes planteados en este estudio, los cuales son en el régimen de sueldos y salarios y el de honorarios profesionales.

En cambio, cuando se les preguntó sobre el régimen de honorarios asimilables al salario se encontró que éste les es confuso, la mayoría no sabía distinguir si existe o no una relación laboral al momento de contratar una persona por este régimen. Esto se puede atribuir a que esta forma de contratar no está claramente definida en ninguna ley, pues como se mostró en el marco teórico del presente estudio y de acuerdo a Chávez (2017) este régimen se regula en la ley del ISR solo en el aspecto del pago del impuesto sobre la renta, también se encontró que no existe una explicación clara por parte de las autoridades del sat en la cual se especifique bajo qué condiciones se puede utilizar, quiénes encuadran en este régimen y qué obligaciones se contraen al contratar por medio de este régimen tanto para los trabajadores como para los patrones.

Tomando en cuenta lo anterior, se puede decir que esto crea confusión entre los directivos y administrativos pues cuando se les preguntó cuántos regímenes fiscales maneja el SAT el 28\% decía que tres, 33\% decía que dos y $22 \%$ no sabía, porque no queda claro si es un régimen fiscal o no para SAT, aun cuando éste sea el que recibe el pago del ISR por los honorarios asimilables al salario.

El régimen de sueldos y salarios se debe de usar cuando se contrata a una persona para ser parte de la estructura organizacional, es decir que cubra un puesto fijo dentro del organigrama y del cual se tenga una certeza económica para cubrir su sueldo, que vaya a estar sujeto a la subordinación de un jefe, con un horario de oficina estipulado, el cual tendrá derecho a todas las prestaciones de ley y con el cual se tendrá una relación laboral. Pero si la contratación del personal está condicionada a un proyecto específico por un tiempo determinado la opción más segura será el régimen de honorarios profesionales.

La principal desventaja que se tiene con el régimen de sueldos y salarios es el alto pago de impuestos que supone contratar bajo este régimen, pues el costo se eleva entre un 40 y $50 \%$ ya que además del monto libre que recibe el trabajador se deben tomar en cuenta el pago de las cuotas obrero patronales ante el IMss, el pago del ISR (impuesto federal) y el impuesto sobre nómina (impuesto estatal).

En cuanto al régimen de honorarios profesionales podemos concluir que se puede utilizar cuando se tenga la necesidad de cubrir un objetivo o 
actividad específica de un proyecto de la organización, por lo cual se tenga que contratar a una persona física con un título profesional para que preste un servicio especializado por un periodo o producto determinado, este tipo de contratos se les conoce como consultorías.

El régimen de honorarios asimilables al salario es una elección que se considera riesgosa porque para el Imss este régimen no existe y para él basta con que haya una subordinación y el pago de una remuneración para demostrar que existe una relación laboral y así poder exigir que una persona contratada por el régimen de honorarios asimilables al salario sea asegurada por su patrón.

Ahora bien, si el régimen de honorarios asimilables al salario no fue solicitado por el trabajador de manera escrita al patrón, el trabajador podría demandar ante las autoridades correspondientes la inscripción en el Imss siempre y cuando demuestre la existencia de la subordinación y la relación laboral de acuerdo al artículo 18 de Lss.

Aun cuando los porcentajes son poco representativos en comparación con la población total, se resaltan estos datos como significativos, ya que se considera como un indicador de la existencia de osc que reciben una sola fuente de financiamiento y tienen la capacidad de manejar todos los regímenes fiscales, lo cual supone un avance para las osc en la formalización del área laboral.

Conforme a los datos recolectados en esta investigación, se considera trascendente señalar que existe un $28 \%$ de los encuestados que dicen que en la osc que laboran no están contratados bajo ninguno de los regímenes mencionados debido a que ellos hacen trabajo voluntario, el cual es manejado como una figura legal sin retribución económica y no como un régimen fiscal. Lo anterior podría suponer una línea de investigación para conocer si el voluntariado es una tendencia que se da en otras osc o solo en las que tienen actividades ambientales, así como conocer las condiciones actuales del voluntariado en las osc.

Otro aspecto que se puede considerar, para afirmar que las fuentes de financiamiento no son un factor que influya a la hora de seleccionar el régimen de contratación, es que en los resultados del presente trabajo se encontró que son pocas las osc que de una sola fuente de financiamiento destinan entre $81 \%$ y $100 \%$ para el pago de los colaboradores y que las que lo hacen son porque son recursos propios, los cuales no están condicionados por un tercero a ejercerse bajo ciertas reglas, como en el caso de los recursos recibidos de la administración pública o de ong o fundaciones donde la entrega del dinero está condicionada a la realización de un proyecto y el seguimiento de un presupuesto, con lo cual se puede decir que las osc usan más de dos fuentes de financiamiento para el pago de sus colaboradores. 
$50 \%$ de los encuestados contestaron que el régimen que más se utiliza en estas osc es el de sueldos y salarios, confirmando que las OSC ambientalistas en Ensenada están buscando ser una fuente de empleo más formal y justa. Cuando se les preguntó por qué el régimen de sueldos y salarios es el más utilizado, el 39\% respondió que es para dar mayor seguridad a los trabajadores y por dar cumplimiento a las leyes laborales, lo cual habla de que los directivos de estas osc están buscando dar empleos formales y seguridad a sus trabajadores, al cuestionarles qué factores consideraban cuando elegían los regímenes de contratación, un 17\% dijo el ingreso poco constante y cambiante lo cual era una limitante para asegurar la continuidad de un contrato por tiempo indefinido, mientras que un $5 \%$ dijo que contrataban más a eventuales por la falta de seguridad en los ingresos que reciben.

De igual forma, este estudio indica que el $61 \%$ de los encuestados tienen contratos firmados con sus colaboradores, observándose que las osc ambientalistas en Ensenada están en proceso de formalizarse por completo.

Podemos ver que las contrataciones más utilizadas en las osc ambientalistas en Ensenada, B.C siguen siendo por tiempo indefinido (33\%), pero también encontramos que los otros tipos de contratos son usados en una forma más pareja que, ya que $27 \%$ de los encuestados dijo que también se usaba el contrato por tiempo o producto definido, $18 \%$ el de honorarios profesionales y $\mathbf{2 2} \%$ por honorarios asimilables al salario, lo cual da muestra de que en las osc se está haciendo uso de los 3 regímenes fiscales que se abordan en este estudio.

Las osc mexicanas están en su mayoría sujetas a fuentes de financiamientos provenientes de terceros (proyectos) lo cual hace que la contratación o continuidad de la fuente de trabajo, o de la misma osc, esté sujeta a la disponibilidad del recurso, lo ideal sería que la fuente de financiamiento más importante y representativa para las osc fuera la generación de recursos propios.

En este trabajo se cuestionó a los participantes si consideraban que las leyes que regulan los diferentes regímenes fiscales eran los adecuados y $50 \%$ de ellos contestaron que no, lo cual se puede considerar como un indicador de esta necesidad.

Como ya se comentó, este sector de las organizaciones sociales brinda una oportunidad para generar nuevas investigaciones que ayuden a conocer sus estrategias diseñadas para brindar mayor seguridad laboral, considerando lo limitado de sus recursos y lo dependiente a las fuentes de financiamiento externo. Resultaría interesante conocer cómo es el clima laboral en este tipo de organizaciones, qué hacen sus dirigentes, ya que a pesar de contar con recursos limitados, las personas siguen motivados a trabajar en las osc. 


\section{REFERENCIAS}

Badillo, Y. (2011). Trabajadores contratados por Honorarios y la violación a sus derechos Laborales (Tesis de licenciatura). México: Universidad Nacional Autónoma de México.

Bañuelos, A. (2016). Implicaciones laborales y de seguro social de los profesionistas con honorarios asimilables a sueldos. Recuperado de: https://arhitac.org/ actualidad/noticias/item/766-implicaciones-laborales-y-de-seguro-socialde-los-profesionistas-con-honorarios-asimilables-a-sueldos.

Comisión de Fomento de las actividades de las Organizaciones de la Sociedad Civil. (26 de marzo de 2017). Reporte de osC. Recuperado de http://166.78.45.36/portal/

Chávez, B. (2017). En asimilables a sueldos ¿se debe emitir un CFDI de nómina? México, D.F. Recuperado de: https://idconline.mx/fiscal-contable/2017/08/30/ en-asimilables-a-sueldos-se-debe-emitir-un-cfdi-de-nomina.

Código Civil Federal. (1928) México. Recuperado de http://www.diputados.gob.mx/LeyesBiblio/pdf/2_241213.pdf

Constitución Política de los Estados Unidos Mexicanos. (1917) México. Recuperado de http://www.diputados.gob.mx/LeyesBiblio/pdf/1_150917.pdf.

De Buen, C. (2005). El contrato de prestación de servicios profesionales, la vía de fraude laboral. Revista Latinoamericana de Derecho. (5). Recuperado de https://archivos.juridicas.unam.mx/www/bjv/libros/3/1090/10.pdf

De Nieto, N. (2009). Las relaciones de trabajo en las entidades sin ánimo de lucro (trabajadores asalariados, cooperantes internacionales, sociostrabajadores y voluntarios). Revista del Ministerio de Trabajo e Inmigración (83), 373-397. Recuperado de http://www.empleo.gob.es/es/publica/ pub_electronicas/destacadas/revista/numeros/83/est15.pdf

Garduño, J., Hernández, A. y Ramírez, L. (2012). Sueldos y Salarios en México (Trabajo final para obtener el grado de licenciatura). Instituto Politécnico Nacional, México, D.F.

Gavilán, B., Iglesias, J. y Beitia, P. (2013). La captación de recursos en el tercer sector. Recuperado de http://www.tercersector.cat/sites/tercersector. cat/files/captacion_recursos_ts._bizkaia.pdf

Hernández, R., Fernández, C., y Baptista, P. (2014). Metodología de la investigación (6 ed.). México: McGraw-Hill/ Interamericana Editores, S.A. de C.V.s/A. (2010). IDC online: asimilables. México, D.F. Recuperado de https://idconline.mx/busqueda?q=asimilables.

Köhler, H. y Artiles, A. (2 ed). (2007). Manual de la sociología del trabajo y de las relaciones laborales. Recuperado de https://books.google.com.mx/ books?hl=es\&lr=\&id=Chcdg_iZzGIC\&oi=fnd\&pg=PA1\&dq=relaciones +1 aborales+en+m\%C3\%A9xico\&ots=K-RdA8L9q4\&sig=30sYu_UfDdhEtB wp54SqI96LIE\#v=onepage \&q\&f=false. 
LFFAOSC. (2012). Ley Federal del Fomento de las actividades de las organizaciones de la Sociedad Civil. México. Recuperado el 1 de 4 de 2017, de http:// www.profeco.gob.mx/juridico/pdf/1_f_actividades.pdf.

LFT (1970). Ley Federal del Trabajo, reforma de 2012. México. Recuperado de http://www.diputados.gob.mx/LeyesBiblio/pdf/125_120615.pdf

LISR (2013). Ley del Impuesto Sobre la Renta. México. Recuperado de http:// www.diputados.gob.mx/LeyesBiblio/pdf/LISR_301116.pdf.

LSS (1995). Ley del Seguro Social. Recuperado de http://www.diputados.gob. $\mathrm{mx} /$ LeyesBiblio/pdf/92_121115.pdf

Mejía, V. (2016). Estrategias financieras para Asociaciones Civiles (Tesis de licenciatura). Universidad Autónoma de México, México, DF.

Nava, T. (2016). Organizaciones De La Sociedad Civil En Baja California: Tras La Ruta De Su Profesionalización (Tesis de Maestría). Colegio de la Frontera Norte. Tijuana, BC.

Pérez, J. y Fol, R. (13 ed). (2017). Taller de Prácticas Laborales y de Seguridad Social. México: Tax Editores Unidos S.A.

Ramos, A. (2012). Efectos del contrato psicológico en una organización no lucrativa (Tesis de maestría). Universidad Autónoma de Nuevo León, Monterrey.

Rojas, K. (2016). Asimilados a Salario, sus Implicaciones en Seguridad Social. México. Recuperado de: http://imcp.org.mx/publicaciones/ asimilados-salario-sus-implicaciones-en-seguridad-social

Sistema de Información del Registro Federal de las osc (SIRFOSC). (2017). Recuperado de http://www.corresponsabilidad.gob.mx/ 